\title{
Açóes e estratégias de educação permanente em saúde na rede de cuidados à pessoa com deficiência
}

\author{
I 1 Suzane Beatriz Frantz Krug, ${ }^{2}$ Guilherme Mocelin, ${ }^{3}$ Maria Carolina Magedanz, \\ ${ }^{4}$ Brenda Raddatz de Oliveira, ${ }^{5}$ Camila Dubow I
}

Resumo: A pesquisa visou investigar ações e estratégias de Educação Permanente em Saúde (EPS) na Rede de Cuidados à Pessoa com Deficiência (PcD), sob a perspectiva de trabalhadores e gestores da saúde. Pesquisa exploratória, tipo estudo de caso, com abordagem mista, realizada nos 13 municípios da Região 28 de Saúde do Rio Grande do Sul, com amostra de 37 sujeitos envolvidos na atenção à saúde das PCDs. Os questionários foram analisados com estatística descritiva, em frequências absolutas e relativas, e as entrevistas por Análise de Conteúdo, culminando três categorias temáticas. Os resultados apontaram que a EPS na Rede de Cuidados às PcDs constitui-se como ferramenta à qualificação das práticas profissionais, mas a maioria dos trabalhadores não participa dessas açóes, pois os municípios não as oferecem. Identificou-se que os sujeitos não reconhecem situações cotidianas de trabalho, espaços e momentos informais, como açóes de EPS. As dificuldades das açóes de EPS foram justificadas pelas inadequadas estruturas físicas dos serviços e baixo quantitativo de profissionais na equipe. Identificou-se pequena quantidade de profissionais envolvidos e reduzido interesse com a temática da $\mathrm{PcD}$, demarcada pela não participação ativa dos usuários dos serviços em ações desse campo. Assim, são indispensáveis reflexões que reconheçam as açóes educativas nos ambientes laborais, transformando-as em práticas cotidianas de atenção à saúde das PCDs.

> Palavras-chave: pessoas com deficiência; Sistema Único de Saúde; trabalho; educação; assistência à saúde.

\author{
${ }^{1}$ Ciências da Saúde, Universidade \\ de Santa Cruz do Sul. Santa Cruz \\ do Sul-RS, Brasil (skrug@unisc.br). \\ ORCID: 0000-0002-2820-019X \\ ${ }^{2}$ Ciências da Saúde, Universidade \\ de Santa Cruz do Sul. \\ Santa Cruz do Sul-RS, Brasil \\ (mocelinguilherme@gmail.com). \\ ORCID: 0000-0001-9727-3619 \\ ${ }^{3}$ Ciências da Saúde, Universidade \\ de Santa Cruz do Sul. Santa Cruz \\ do Sul-RS, Brasil (carolmagedanz@ \\ gmail.com). \\ ORCID: 0000-0002-0461-2018 \\ ${ }^{4}$ Ciências da Saúde, Universidade \\ de Santa Cruz do Sul. Santa Cruz \\ do Sul-RS, Brasil (brendaraddatzz. \\ br@gmail.com). \\ ORCID: 0000-0002-9116-2720 \\ ${ }^{5}$ Ciências da Saúde, Universidade \\ de Santa Cruz do Sul. Santa Cruz \\ do Sul-RS, Brasil (camiladubow@ \\ yahoo.com.br). \\ ORCID: 0000-0002-6853-8697
}

Recebido em: 15/07/2020

Aprovado em: 17/11/2020 Revisado em: 29/03/2021 


\section{Introdução}

A Política Nacional de Saúde da Pessoa com Deficiência, instituída por meio da Portaria no 1.060/2002, visa a proteçáo à saúde das pessoas com deficiência, reabilitação de suas capacidades funcionais e desempenho humano, corroborando a inclusão social e melhoria da qualidade de vida, bem como auxílio na prevenção de agravos e promoção da saúde (BRASIL, 2010a). Desse modo, a referida política preconiza atendimentos qualificados às necessidades particulares desses indivíduos e familiares, considerando os sujeitos e suas subjetividades em seu contexto biopsicossocial.

Em 2010, o Brasil possuía 23,9\% da população com algum tipo de deficiência (IBGE, 2010), o que contribuiu para a implementação da Rede de Cuidados à Pessoa com Deficiência (RCPD), através da Portaria no 793/2012, com o objetivo de ampliar e qualificar o cuidado no atendimento prestado, além de articular os serviços de reabilitação com a rede de atenção primária e outros pontos de atenção especializada (DUBOW; GARCIA; KRUG, 2018). Importante destacar que essa portaria apresenta, entre suas diretrizes, a promoção de estratégias de Educação Permanente para o funcionamento da Rede (BRASIL, 2012).

A Educação Permanente em Saúde (EPS) se caracteriza como "uma estratégia político-pedagógica para a formação e desenvolvimento dos trabalhadores para o Sistema Único de Saúde (SUS)" (SANTOS; RAMOS; QUEIROZ, 2017, p. 63). Efetiva-se a partir das práticas educativas que buscam o aperfeiçoamento constante das formas de trabalho baseando-se, principalmente, na demanda das populações atendidas, ajustando os serviços ofertados, com o intuito de garantir assistência de qualidade. Assume o protagonismo da gestão da educação, ao propor mudanças nas açóes educativas, nos processos de trabalho, nas organizaçóes de saúde e, principalmente, no desenvolvimento de estratégias que possam auxiliar na qualificação da atenção em saúde (BRASIL, 2007).

Os processos de Educação Permanente dos trabalhadores da saúde têm como premissa a problematização do seu processo de trabalho, de modo a incentivar a promoção e a prevenção por meio de intervençôes educativas em saúde, tendo como referência as necessidades de saúde das pessoas e das populaçôes, mediante a realidade do contexto de trabalho e do usuário (PERES; SILVA; BARBA, 2016). Por meio de estratégias educativas no trabalho em saúde que promovam transformações nas 
práticas profissionais e na organização do trabalho, é possível atenuar dificuldades do cotidiano dos trabalhadores nos espaços que envolvem a assistência à saúde (AMORIM; LIBERALI; MEDEIROS NETA, 2018). Nesse escopo, a Política Nacional de Educação Permanente em Saúde (PNEPS) estabelece orientaçôes e diretrizes que incorporam o aprender e o ensinar em um processo de relação entre a educação e a saúde no cotidiano do trabalho, estimulando o protagonismo do trabalhador nesse cenário (BRASIL, 2009). Nessa perspectiva, mostra-se necessário que os trabalhadores de saúde estejam preparados para atender às demandas das pessoas com deficiência, observando-se a indispensabilidade das açóes de EPS no âmbito da Rede de Cuidados à Pessoa com Deficiência no SUS.

Diante desses pressupostos, tornam-se relevantes as práticas educativas em saúde voltadas a temática da pessoa com deficiência para os profissionais da rede de cuidados. Nesse sentido, a EPS é uma condição para o desenvolvimento da escuta qualificada e da produção das aprendizagens de cuidado orientadas para a resolutividade dos problemas de saúde dessa população, permitindo a construção da acessibilidade da atenção e do sistema de saúde (CECCIM, 2005).

Destaca-se a importância de estudos que demonstram realidades dessas ações de EPS na Rede de atenção à pessoa com deficiência em distintos panoramas geográficos do Brasil. Assim, o objetivo deste estudo foi investigar as açóes e estratégias de Educação Permanente em Saúde na Rede de Cuidados à Pessoa com Deficiência em uma região de saúde do Rio Grande do Sul, sob a perspectiva de trabalhadores e gestores da saúde.

\section{Material e Método}

Realizou-se estudo de caso, por meio de pesquisa exploratória, que empregou estratégias de investigação mista, quantitativa e qualitativa para mapear, descrever e analisar o contexto, relaçóes e percepçóes a respeito do tema.

O estudo foi realizado na Região 28 de Saúde do Rio Grande do Sul, localizada na regiâo central do estado, onde vive uma população estimada de 327.158 habitantes, distribuída em 13 municípios e que possui $30,81 \%$ da população com algum tipo de deficiência (IBGE, 2010). A Rede de Atenção à Saúde da regiáo constitui-se de atenção primária, secundária e terciária, e está organizada em 51 Estratégias Saúde da Família (ESF), 44 Unidades Básicas de Saúde (UBS), nove equipes de Núcleo de 
Apoio à Saúde da Família (NASF), um serviço de reabilitação física, dois serviços de reabilitação intelectual e três hospitais gerais com mais de 80 leitos (DUBOW, 2017).

A amostra foi composta por 37 trabalhadores da saúde pertencentes aos segmentos - 10 secretários municipais de Saúde (S), 14 profissionais da saúde (P) e 13 coordenadores de serviços de reabilitação $(\mathrm{C})$ envolvidos na atenção à saúde das pessoas com deficiência. Esses sujeitos representam diferentes níveis de participação dos contextos municipais e regional, permitindo melhor assimilação das ações de Educação Permanente em Saúde da Rede sob diferentes perspectivas, conforme a realidade da qual os sujeitos falam ou atuam. Considerou-se, em amostragem intencional, um conjunto de informantes que possibilitou a apreensão de semelhanças e diferenças nas respostas, bem como um número de sujeitos suficiente para permitir a reincidência das informaçóes.

Para a coleta de dados, realizada de maio a outubro de 2016, foram utilizados dois instrumentos em momentos distintos: questionários e entrevistas semiestruturadas. Os dados coletados através do questionário permitiram uma visão mais genérica e ampliada do contexto estudado; em contrapartida, as entrevistas contribuíram para o aprofundamento das percepçóes e concepçóes dos sujeitos a respeito da temática na regiâo. Inicialmente, foi realizada testagem piloto dos instrumentos com representantes de cada segmento para avaliação dos mesmos quanto à sua apresentação e compreensão, não havendo necessidade de adequaçôes. Após, foram aplicados os questionários com 37 sujeitos e, em seguida, realizadas entrevistas com sete sujeitos, gravadas em mídia digital mediante consentimento prévio e transcritas em sua íntegra.

Os dados dos questionários foram analisados em estatística descritiva, com frequências absolutas e relativas. Para as entrevistas, utilizou-se a técnica Análise de Conteúdo, cumprindo as etapas de pré-análise, com leitura compreensiva dos textos transcritos; exploração do material visando a alcançar o núcleo de compreensão do texto por meio da elaboração de categorias de análise e agrupar trechos de depoimentos significativos; e tratamento dos resultados obtidos e interpretação dos dados (BARDIN, 2016). Nos resultados e discussão, apresentam-se algumas falas dos sujeitos pesquisados.

$\mathrm{O}$ processo de análise qualitativa culminou em três categorias temáticas, que discutiram também os dados quantitativos, articulando as abordagens de análise 
dos dados. A primeira categoria temática, denominada "Atividades de Educação Permanente na Rede de atenção à saúde da pessoa com deficiência", permitiu a análise e reflexão sobre os potenciais e perspectivas dessas atividades; a segunda categoria, "Dificuldades de efetivação das açôes de Educação Permanente na Rede de saúde à pessoa com deficiência", tratou de situações que interferem na realização de atividades de EPS nos municípios investigados; a terceira categoria, intitulada "Perspectivas dos trabalhadores acerca das temáticas de EPS", aborda sugestóes de atividades de Educação Permanente em Saúde na região estudada.

Salienta-se, ainda, a inter-relação entre as três categorias de análise, apresentadas de maneira isolada neste texto para melhor compreensão dos aspectos fundamentais abordados em cada uma delas. Contudo, destaca-se que a participação em açôes e estratégias de Educação Permanente em Saúde na Rede de Cuidados à Pessoa com Deficiência apresentadas e discutidas na primeira categoria estão diretamente relacionadas aos motivos da não adesão a essas açôes, apresentadas na segunda categoria, e às sugestóes de temáticas de atividades pontuais, como cursos e capacitaçóes, discutidas na terceira categoria, não podendo, portanto, ser entendidas de maneira isolada, assim como são as vivências de Educação Permanente em Saúde presentes no cotidiano de trabalho.

Em cumprimento aos requisitos éticos da Resolução no 466/2012 do Conselho Nacional de Saúde, o projeto foi aprovado pelo Comitê de Ética em Pesquisa da Universidade de Santa Cruz do Sul, sob o protocolo $1.300 .666 / 15$, e todos os participantes assinaram o Termo de Consentimento Livre e Esclarecido. Para garantir o anonimato dos participantes, as narrativas foram identificadas com o uso de letras, acompanhadas de numeração por segmentos.

\section{Resultados e Discussão}

Os sujeitos do estudo que responderam o questionário ( $\mathrm{n}=37)$ foram, em sua maioria, do sexo feminino, com idades entre 29 e 39 anos e pós-graduados. O segmento de maior número de sujeitos no estudo foi o de profissionais da saúde $(n=14)$. Dentre os participantes, predominou a profissão de enfermeiro $(n=13)$, sendo que a maioria destes eram coordenadores de serviços de reabilitação $(\mathrm{n}=10)$. Os demais dados referentes ao perfil dos sujeitos estão dispostos na tabela 1 . 
Tabela 1. Perfil sociodemográfico e ocupacional dos respondentes dos questionários. Regiáo 28 de Saúde - Rio Grande do Sul, 2017

\begin{tabular}{|c|c|c|c|c|c|c|c|c|}
\hline Variáveis & $\begin{array}{l}\text { Profissionais } \\
\text { (p) }\end{array}$ & $\%$ & $\begin{array}{l}\text { Coordenadores } \\
\text { (c) }\end{array}$ & $\%$ & $\begin{array}{l}\text { Secretários } \\
\text { municipais } \\
\text { de saúde (s) }\end{array}$ & $\%$ & Total & $\%$ \\
\hline \multicolumn{9}{|l|}{ Sexo } \\
\hline Feminino & 11 & 29,7 & 13 & 35,1 & 6 & 16,2 & 30 & 81 \\
\hline Masculino & 3 & 8,2 & 0 & 0 & 4 & 10,8 & 7 & 19 \\
\hline \multicolumn{9}{|l|}{ Faixa etária } \\
\hline $18-28$ & 3 & 8,2 & 1 & 2,7 & 0 & 0 & 4 & 10,9 \\
\hline $29-39$ & 5 & 13,4 & 7 & 18,9 & 2 & 5,4 & 14 & 37,7 \\
\hline $40-50$ & 5 & 13,4 & 2 & 5,4 & 4 & 10,8 & 11 & 29,6 \\
\hline $51-60$ & 1 & 2,7 & 3 & 8,2 & 1 & 2,7 & 5 & 13,6 \\
\hline$>61$ & 0 & 0 & 0 & 0 & 3 & 8,2 & 3 & 8,2 \\
\hline \multicolumn{9}{|l|}{ Formação } \\
\hline Ensino médio & 0 & 0 & 0 & 0 & 2 & 5,4 & 2 & 5,4 \\
\hline Superior & 5 & 13,4 & 2 & 5,4 & 4 & 10,8 & 11 & 29,6 \\
\hline $\begin{array}{l}\text { Superior } \\
\text { incompleto }\end{array}$ & 1 & 2,7 & 0 & 0 & 1 & 2,7 & 2 & 5,4 \\
\hline Pós-graduação & 8 & 21,7 & 11 & 29,7 & 3 & 8,2 & 22 & 59,6 \\
\hline \multicolumn{9}{|l|}{ Profissão } \\
\hline Administrador & 0 & 0 & 0 & 0 & 2 & 5,4 & 2 & 5,4 \\
\hline Assistente social & 1 & 2,7 & 0 & 0 & 1 & 2,7 & 2 & 5,4 \\
\hline Dentista & 1 & 2,7 & 0 & 0 & 0 & 0 & 1 & 2,7 \\
\hline $\begin{array}{l}\text { Educador } \\
\text { especial }\end{array}$ & 0 & 0 & 1 & 2,7 & 0 & 0 & 1 & 2,7 \\
\hline Empresário & 0 & 0 & 0 & 0 & 1 & 2,7 & 1 & 2,7 \\
\hline Enfermeiro & 2 & 5,4 & 10 & 27 & 1 & 2,7 & 13 & 35 \\
\hline Fisioterapeuta & 2 & 5,4 & 1 & 2,7 & 0 & 0 & 3 & 8,2 \\
\hline Médico & 1 & 2,7 & 0 & 0 & 2 & 5,4 & 3 & 8,2 \\
\hline
\end{tabular}




\begin{tabular}{|c|c|c|c|c|c|c|c|c|}
\hline Variáveis & $\begin{array}{l}\text { Profissionais } \\
\text { (p) }\end{array}$ & $\%$ & $\begin{array}{c}\text { Coordenadores } \\
\text { (c) }\end{array}$ & $\%$ & $\begin{array}{l}\text { Secretários } \\
\text { municipais } \\
\text { de saúde (s) }\end{array}$ & $\%$ & Total & $\%$ \\
\hline Nutricionista & 1 & 2,7 & 0 & 0 & 0 & 0 & 1 & 2,7 \\
\hline Psicólogo & 3 & 8,2 & 1 & 2,7 & 0 & 0 & 4 & 10,8 \\
\hline $\begin{array}{l}\text { Secretário } \\
\text { municipal saúde }\end{array}$ & 0 & 0 & 0 & 0 & 2 & 5,4 & 2 & 5,4 \\
\hline $\begin{array}{l}\text { Técnico } \\
\text { enfermagem }\end{array}$ & 2 & 5,4 & 0 & 0 & 0 & 0 & 2 & 5,4 \\
\hline Náo informado & 1 & 2,7 & 0 & 0 & 1 & 2,7 & 2 & 5,4 \\
\hline \multicolumn{9}{|l|}{ Local de atuação } \\
\hline EACS & 0 & 0 & 1 & 2,7 & 0 & 0 & 1 & 2,7 \\
\hline ESF & 3 & 8,2 & 5 & 13,5 & 0 & 0 & 8 & 21,6 \\
\hline Hospital & 1 & 2,7 & 1 & 2,7 & 0 & 0 & 2 & 5,4 \\
\hline NASF & 2 & 5,4 & 0 & 0 & 0 & 0 & 2 & 5,4 \\
\hline $\begin{array}{l}\text { Secretaria } \\
\text { municipal de } \\
\text { saúde }\end{array}$ & 0 & 0 & 0 & 0 & 10 & 27 & 10 & 27 \\
\hline $\begin{array}{l}\text { Serviço } \\
\text { reabilitaçáo física }\end{array}$ & 1 & 2,7 & 1 & 2,7 & 0 & 0 & 2 & 5.4 \\
\hline $\begin{array}{l}\text { Serviço de } \\
\text { reabilitaçáo } \\
\text { intelectual }\end{array}$ & 1 & 2,7 & 1 & 2,7 & 0 & 0 & 2 & 5,4 \\
\hline Ubs & 5 & 13,5 & 3 & 8,2 & 0 & 0 & 8 & 21,7 \\
\hline Outro & 1 & 2,7 & 1 & 2,7 & 0 & 0 & 2 & 5,4 \\
\hline \multicolumn{9}{|l|}{$\begin{array}{l}\text { Tempo de } \\
\text { atuaçáo }\end{array}$} \\
\hline$<1$ ano & 5 & 13,4 & 0 & 0 & 5 & 13,4 & 10 & 27 \\
\hline $1-5$ anos & 5 & 13,4 & 4 & 10,8 & 4 & 10,8 & 13 & 35 \\
\hline $6-10$ anos & 1 & 2,7 & 4 & 10,8 & 0 & 0 & 5 & 13,5 \\
\hline 11-20 anos & 3 & 8,2 & 5 & 13,4 & 1 & 2,7 & 9 & 24,5 \\
\hline Total & 14 & 37,8 & 13 & 35,1 & 10 & 27 & 37 & 100 \\
\hline
\end{tabular}

Fonte: dados da pesquisa, 2017. 
Em relação ao perfil dos sujeitos que responderam à entrevista $(n=7)$, todos eram do sexo feminino; a maioria com idade entre 29 e 39 anos $(n=3)$; pertencentes à categoria de coordenadores de serviços de reabilitação $(n=4)$, dentre os quais enfermeiros ( $\mathrm{n}=2)$, com atuação em Reabilitação Intelectual $(\mathrm{n}=3)$. Quanto ao tempo de exercício, o tempo de trabalho variou entre 11 e 20 anos $(n=4)$, conforme descrito na tabela 2.

Tabela 2. Perfil sociodemográfico e ocupacional dos respondentes da entrevista. Região 28 de Saúde - Rio Grande do Sul, 2017

\begin{tabular}{|c|c|c|c|c|}
\hline Variáveis & Profissionais (p) & Coordenadores (c) & $\begin{array}{c}\text { Secretários } \\
\text { municipais de } \\
\text { saúde (s) }\end{array}$ & Total \\
\hline \multicolumn{5}{|l|}{ Sexo } \\
\hline Feminino & 2 & 4 & 1 & 7 \\
\hline \multicolumn{5}{|l|}{ Faixa etária } \\
\hline $29-39$ & 1 & 2 & 0 & 3 \\
\hline $40-50$ & 1 & 0 & 0 & 1 \\
\hline $51-60$ & 0 & 2 & 0 & 2 \\
\hline$>61$ & 0 & 0 & 1 & 1 \\
\hline \multicolumn{5}{|l|}{ Formaçáo } \\
\hline Superior & 1 & 1 & 0 & 2 \\
\hline Superior incompleto & 0 & 0 & 1 & 1 \\
\hline Pós-graduação & 1 & 3 & 0 & 4 \\
\hline \multicolumn{5}{|l|}{ Profissão } \\
\hline Assistente social & 1 & 0 & 0 & 1 \\
\hline Educador especial & 0 & 1 & 0 & 1 \\
\hline Enfermeiro & 1 & 1 & 0 & 2 \\
\hline Fisioterapeuta & 0 & 1 & 0 & 1 \\
\hline Psicólogo & 0 & 1 & 0 & 1 \\
\hline Secretário de saúde & 0 & 0 & 1 & 1 \\
\hline
\end{tabular}

continua... 


\begin{tabular}{|c|c|c|c|c|}
\hline Variáveis & Profissionais (p) & Coordenadores (c) & $\begin{array}{l}\text { Secretários } \\
\text { municipais de } \\
\text { saúde (s) }\end{array}$ & Total \\
\hline \multicolumn{5}{|l|}{ Local de atuação } \\
\hline Eacs & 0 & 1 & 0 & 1 \\
\hline Hospital & 1 & 1 & 0 & 2 \\
\hline $\begin{array}{l}\text { Secretaria municipal de } \\
\text { saúde }\end{array}$ & 0 & 0 & 1 & 1 \\
\hline $\begin{array}{l}\text { Serviço de reabilitação } \\
\text { física }\end{array}$ & 0 & 1 & 0 & 1 \\
\hline $\begin{array}{l}\text { Serviço de reabilitação } \\
\text { intelectual }\end{array}$ & 1 & 1 & 0 & 2 \\
\hline \multicolumn{5}{|l|}{ Tempo de atuação } \\
\hline$<1$ ano & 0 & 0 & 1 & 1 \\
\hline $1-5$ anos & 1 & 1 & 0 & 2 \\
\hline 6-10 anos & 0 & 2 & 0 & 2 \\
\hline $11-20$ anos & 1 & 1 & 0 & 2 \\
\hline Total & 2 & 4 & 1 & 7 \\
\hline
\end{tabular}

Fonte: dados da pesquisa, 2017.

A seguir, são apresentadas as três categorias temáticas elaboradas a partir da análise dos dados obtidos no estudo.

\section{Atividades de Educação Permanente na Rede de Atenção à Saúde da Pessoa com Deficiência}

A EPS, como sinônimo de aprendizagem ativa e significativa no trabalho, transforma as práticas profissionais, aprimorando-as conforme a realidade e contexto dos serviços de saúde em que os profissionais estão inseridos (PINHEIRO; AZAMBUJA; BONAMIGO, 2018). Em relação aos profissionais atuantes na Rede de Cuidados à Pessoa com Deficiência, a capacitaçáo permanente proporciona integralidade e impede a descontinuidade assistencial, culminando em intervençóes singulares que, em redes, proporcionam encaminhamentos, favorecendo a capilaridade e a gestáo coordenada do cuidado (MACHADO et 
al., 2018). Além disso, a EPS caracteriza-se como um dos princípios norteadores da Rede de Cuidados que visa mudanças significativas no pensar e no agir dos profissionais no campo da saúde (MENDES, 2014).

Compreende-se, assim, que as responsabilidades não são intrínsecas somente aos profissionais atuantes, mas cabe também às instituiçóes mantenedoras a responsabilidade de aperfeiçoamento de práticas, por meio da relação entre a realidade do trabalho e conhecimentos construídos, a fim de suprir satisfatoriamente a demanda do meio atuante. Entende-se como "necessário que processos educativos estejam inseridos no dia a dia dos profissionais, para que os serviços estejam preparados para prestar assistência de forma adequada aos diferentes públicos que necessitam de cuidado" (PINHEIRO; AZAMBUJA; BONAMIGO, 2018, p. 188).

O presente estudo apontou para lacunas no que se refere a ocorrência e participaçáo em açôes educativas voltadas à Rede de Cuidado à Pessoa com Deficiência nos municípios e/ou locais de trabalho, tendo em vista que grande parte dos sujeitos $(\mathrm{n}=26)$ relatou a não participação nessas ações, especificamente em seus locais de atuaçâo, no período questionado. Ainda, pode-se identificar o desconhecimento dos sujeitos $(\mathrm{n}=2)$ acerca da realização dessas atividades durante este período. A tabela 3 descreve esses dados destacando que, dentre os três segmentos de sujeitos, os profissionais de saúde foram os que menos referiram a ocorrência dessas atividades em seus locais de trabalho.

Tabela 3. Participação em atividades de Educação Permanente. Regiẫo 28 de Saúde Rio Grande do Sul, 2017

\begin{tabular}{l|c|c|c|c}
\hline \multicolumn{1}{|c|}{ Variáveis } & $\begin{array}{c}\text { Profissionais } \\
\mathbf{n}(\%)\end{array}$ & $\begin{array}{c}\text { Coordenadores } \\
\mathbf{n}(\%)\end{array}$ & $\begin{array}{c}\text { Secretários } \\
\text { municipais de Saúde } \\
\mathbf{n}(\%)\end{array}$ & $\begin{array}{c}\text { Total } \\
\mathbf{n}(\%)\end{array}$ \\
\hline Sim $(24,3)$ & $3(8,1)$ & $5(13,5)$ & $1(2,7)$ & 9 \\
\hline Não $(70,3)$ & $11(29,7)$ & $8(21,6)$ & $7(18,9)$ & 26 \\
\hline Não sei $(5,4)$ & $0(0)$ & $0(0)$ & $2(5,4)$ & 2 \\
\hline Total $(\mathbf{1 0 0})$ & $\mathbf{1 4}$ & $\mathbf{1 3}$ & $\mathbf{1 0}$ & $\mathbf{3 7}$ \\
\hline
\end{tabular}

Fonte: dados da pesquisa, 2017

Em contrapartida aos dados supracitados evidenciados neste estudo, e em relação à realização de ações de EPS não necessariamente voltados aos cuidados da pessoa 
com deficiência, pesquisa realizada no Mato Grosso do Sul com 184 Equipes de Saúde da Família, utilizando os dados provenientes do primeiro ciclo da fase de Avaliação Externa do Programa Nacional de Melhoria do Acesso e da Qualidade da Atenção Básica, identificou que 92,9\% (171) dos entrevistados relataram que as açóes de EPS estiveram presentes no cotidiano das equipes de saúde. Todavia, a predominância de cursos presenciais relatados como as açóes mais realizadas pelas equipes, tanto na capital quanto no interior, indica que a essência e a complexidade da proposta da EPS, possivelmente, não tenham sido aprofundadas o suficiente para uma mudança de paradigma (MACHADO et al., 2015).

A incipiência das ações de Educação Permanente também foi identificada em pesquisa que avaliou de que forma vêm sendo utilizadas as açóes concernentes à Educação Permanente em Saúde nos serviços de saúde no estado do Rio Grande do Sul. O estudo evidenciou a existência de programas educativos na maioria das instituições hospitalares, mas, mesmo presentes, eram modestos, compartimentados, não seriados, pouco sistematizados, assim como não tinham embasamento teóricoeducativo, pois eram empiricamente reproduzidos (SILVA et al., 2016).

Em outro estudo, ficou evidente que as açôes de EPS se materializam em cursos de capacitação para uma categoria profissional específica, com datas de início e fim, definidas previamente, com temas predeterminados e não advindas do processo de trabalho das unidades de saúde; ou seja, sem a participação ativa do trabalhador no planejamento das atividades. Assim, caracterizam-se como atividades verticalizadas e esporádicas de educação, destinadas a um público-alvo específico, os trabalhadores (PERES; SILVA; BARBA, 2016; FORTUNA et al., 2013).

Essas características podem ser encontradas no modelo de Educação Continuada, definida como um conjunto de atividades voltadas à atualização do trabalhador, sendo oportunizado o desenvolvimento crítico e criativo do mesmo, assim como sua participação eficaz no cotidiano da instituição. Trata-se de um conjunto de atividades educativas, individuais ou coletivas que consideram a realidade profissional, abrangendo não só o conhecimento ofertado em treinamentos, capacitaçóes e atualizaçôes nos modelos tradicionais, como também comporta momentos de valorização e crescimento pessoal no trabalho; dessa forma, eleva a autoestima, permitindo a experimentação da autonomia no desempenho profissional. Por outro lado, a Educação Permanente é um processo contínuo que promove o desenvolvimento integral dos trabalhadores, utilizando situaçóes do trabalho para 
uma aprendizagem significativa, considerando as necessidades do profissional e a inovação tecnológica (PEIXOTO, 2013).

Essa autora inclui, ainda, a Educação em Serviço como prática educativa integrada ao processo de educação no trabalho, conceituando-a como um processo a ser aplicado nas relaçóes humanas e do trabalho. Objetiva o desenvolvimento da capacidade cognitiva, psicomotora e relacional, assim como o aperfeiçoamento diante da evolução tecnológica contribuindo para a valorização profissional e institucional (PEIXOTO, 2013).

Sendo assim, as ações de Educação Permanente em Saúde no âmbito da atenção à pessoa com deficiência na região estudada, e que pressupóem a troca de informações, educação participativa e aperfeiçoamento das práticas cotidianas do trabalho, em uma abordagem voltada às necessidades coletivas dos trabalhadores de saúde, geralmente não ocorrem nesses espaços de trabalho. As práticas educativas ainda se encontram centradas nas características dos modelos e processos de Educação Continuada e de Educação em Serviço.

\section{Dificuldades de efetivação das açóes de Educação Permanente na Rede de saúde à pessoa com deficiência}

A implementação de estratégias de Educação Permanente dos profissionais é uma prioridade para o desenvolvimento de atividade de atençáo às PcDs, sendo, inclusive, uma das diretrizes para o funcionamento da rede de cuidados à pessoa com deficiência (BRASIL, 2012).

A Educaçáo Permanente em Saúde emerge com a finalidade de reestruturação e capacitação continuada dos modelos de atenção primária, suprindo necessidades de acessibilidade, atendimentos e gestão da sociedade adscrita no quesito pessoa com deficiência e sociedade em geral (MENDES, 2014). Para tanto, existe a necessidade de educaçáo constante entre todos os profissionais envolvidos na Rede de atençáo à população, qualificando e efetivando os trabalhadores. Compreende-se, no entanto, que por vezes essas capacitações não ocorrem de forma atrativa, enfraquecendo o potencial educativo dessas e, consequentemente, a qualidade dos serviços. Alguns dos fatores que fazem com que as açóes educativas deixem de ser potencialmente valorativas se identificam com o local de ocorrência e os responsáveis para tal, tendo em vista serem profissionais da própria equipe, em grandes porções, que as ministram (MENDES, 2014; PINHEIRO; AZAMBUJA; BONAMIGO, 2018). 
$\mathrm{Na}$ esteira dessas consideraçóes, os sujeitos do presente estudo apontaram dificuldades semelhantes na realização das atividades de EPS nos municípios investigados e que se traduzem em situaçôes de precariedade da estrutura física para tais eventos, e também na quantidade reduzida de trabalhadores de saúde para o desenvolvimento e participação nas mesmas. Essas situações centram-se em uma abordagem focada exclusivamente em atividades educativas pontuais, como cursos e capacitações:

[...] Mas gostaria de fazer com mais frequência, mas aí teria que ter mais profissionais na equipe (S5).

Em consonância aos achados da pesquisa, observou-se que em estudo desenvolvido em Estratégias Saúde da Família, no estado da Paraíba, açôes de Educação Permanente são entendidas como de Educação Continuada, sendo reconhecidas como momentos de capacitação propriamente ditos, em que existe um ator principal de disseminação e propagação de conhecimentos centrais e especializados. Evidencia-se, assim, o não reconhecimento de ações informais de EPS, tais como rodas de conversas e rounds discursivos que englobam assuntos pertinentes a casos de pacientes, por exemplo (CAVALCANTI; PADILHA, 2014).

Em outro estudo realizado em um município do interior do Rio Grande do Sul, também foram encontradas dificuldades na execução e participação de atividades de Educação Permanente nos serviços da Rede de atenção à saúde municipal, justificando como entraves a infraestrutura inadequada do serviço, excesso de demandas de trabalho, não adesão de alguns profissionais e incompreensão das açôes de educação desenvolvidas. Houve também dificuldades de aceitação por parte da população, já que os profissionais precisam explicar e reiterar a importância das atividades educativas, com o objetivo de melhorar a assistência à saúde. Dessa forma, seria interessante se houvesse um envolvimento dos usuários no processo de EPS (PINHEIRO; AZAMBUJA; BONAMIGO, 2018).

A respeito da participação do usuário nos serviços de saúde, além da composição multiprofissional e escopo interdisciplinar, as equipes devem fomentar o envolvimento das PcDs, suas famílias, unidades de saúde e comunidades, articulando recursos em prol da efetiva inclusão das pessoas com deficiência (BRASIL, 2010b). Frente a sua complexidade, as ações em assistência e reabilitação não podem ser realizadas a partir do trabalho de somente um saber ou campo profissional, mas a partir de uma 
lógica de trabalho coletivo, por equipes multiprofissionais e interdisciplinares, com o envolvimento direto da pessoa com deficiência, seus familiares e/ou assistentes nos processos de cuidado (BRASIL, 2020).

Historicamente, no Brasil, a Educação Permanente, como política pública e dispositivo de reflexão coletiva de transformação do trabalho, consolidou-se somente a partir dos anos 2000 com a PNEPS. Porém, desde 1970, existe a ideia de aperfeiçoamento das práticas em saúde, por meio do "adestramento" (p. 4-5) dos trabalhadores com vistas a desenvolver habilidades técnicas que adequassem esse sujeito ao seu posto de trabalho e às necessidades dos serviços. A ruptura da ideia de educação em saúde por meio de um "adestramento" (p. 4-5) e da construção de um ideal de educação continuada, do diálogo e da interação entre os diversos profissionais e práticas presentes nos serviços começa a ser introduzida na realidade nacional somente a partir da década de 1980 (SILVA et al., 2019). Sendo assim, a ideia de Educação Permanente como aprendizagem ativa, significativa e transformadora, bem como os percursos científicos trilhados, ainda se fazem recentes nesse campo.

Conforme supracitado, evidenciou-se no presente estudo que, embora as ações de Educação Permanente já permeiam os espaços da Rede de Cuidados à Pessoa com Deficiência, elas não são identificadas como tal. Sendo assim, ainda prevalece a busca por temáticas específicas e demasiadamente especializadas das ações educativas na Rede, especialmente para as atividades de capacitação. Estas se mostraram adequadas às necessidades individuais dos trabalhadores da saúde e pouco articuladas às necessidades da equipe de trabalho e dos usuários, em uma abrangência náo coletiva do processo de trabalho e da assistência voltada às reais demandas das PcDs. Atravessados por essa visão tradicional e muitas vezes estigmatizada acerca da temática, na perspectiva das atividades de capacitação profissionalizante, os sujeitos referiram como exemplos, atividades de palestras e minicursos/cursos:

Específico assim, geral, não. Mas cada um procura na sua área. Então vários profissionais participaram de capacitaçóes, por exemplo. (P13)

[...] individualmente cada profissional procura os cursos, né. [...] (C2)

Goffman (2012) refere que, mesmo com importantes avanços, ainda é marcante a presença de estigma e estereótipos perante as PcDs, evidenciando o despreparo da sociedade para lidar com as diferenças, resultando em preconceito e discriminação, até mesmo em serviços de saúde. Isto ressalta a necessidade impreterível de que a 
deficiência passe a ser vista como um aspecto da diversidade humana, deixando de ser sinônimo de desvantagem natural e transferindo para as sociedades a responsabilidade em promover igualdade entre pessoas com e sem deficiência, e a equidade como princípio do SUS na assistência à saúde, de forma a atender suas demandas e necessidades (SANTOS, 2016).

Estudo desenvolvido em Secretarias de Saúde permitiu constar que as práticas de Educação Permanente informadas pelos municípios não guardam relação exclusiva com o tipo de concepção pedagógica dessas estratégias. Ou seja, os dados apontaram que, no cotidiano dos gestores municipais, existe pouca preocupação em relacionar EPS como ações educativas voltadas à reflexão para intervenção, na perspectiva de superar problemas práticos do serviço, transformando a realidade. Termos como capacitação, qualificação, educação continuada, Educação Permanente, curso, atualização, treinamento e atividades que envolvem a comunidade foram usados indistintamente, nomeando práticas similares até em um mesmo município (SENA et al., 2017).

Como exemplo de atividades educativas ainda entrelaçadas por visões tradicionais, os nove indivíduos da tabela 3, que afirmaram ter participado de atividades educativas em saúde no campo da atençáo à pessoa com deficiência, referiram a abordagem de temas centrados no atendimento de crianças com microcefalia; atendimento à pessoa com deficiência múltipla; qualificação em órteses, próteses e meios auxiliares de locomoção. De um modo geral, a partir das falas e dos temas de atividades educativas por eles referidos, experiências de capacitação individuais podem ser observadas estando relacionadas às necessidades particulares de cada profissional, como por exemplo a participação em congressos, seminários e eventos relacionados à sua área.

Nesse sentido, práticas de Educação Permanente voltadas a temática da pessoa com deficiência que deveriam ocorrer coletivamente nos serviços de saúde do SUS por vezes ocorrem de modo incipiente e não reconhecidas como tais (QUEIROZ; SILVA; OLIVEIRA, 2014). Portanto, "são inegáveis os esforços que vêm sendo empreendidos com processos de formação e qualificação profissional no Sistema Único de Saúde, todavia, sem atingir a transformação desejada nas práticas de saúde" (VERMELHO; FIGUEIREDO, 2017, p. 384). Estudo realizado na rede de atenção primária do município do Porto Alegre, ao buscar facilidades e dificuldades no atendimento de usuários com deficiência, evidenciou que os profissionais encontram-se desqualificados, possuindo fragilidades na assistência a esse público, 
o que estaria relacionado às infrequentes capacitaçóes, trazendo desafios para a elaboração de práticas de saúde resolutivas e efetivas, bem como a desfragmentação do cuidado às pessoas com deficiência (TEDESCO; JUNGES, 2013).

Nessa perspectiva, compreende-se que as estratégias de EPS devem se articular às demandas encontradas nos meios de trabalho, levando em consideração as fragilidades identificadas, o que contribui para a qualificação da assistência (PERES; SILVA; BARBA, 2016). Por meio de espaços de capacitação e estratégias para reflexão diante dos problemas e desafios da saúde pública nos municípios e regiōes, é possível enfrentar o desafio de produzir transformaçôes nas práticas profissionais e na própria organização do trabalho (BATISTA; GONÇALVES, 2011). Nesse sentido, a Educação Permanente em Saúde é uma condição para o desenvolvimento de escuta qualificada e produção das aprendizagens de cuidado, relativas à intervenção no andar da vida individual e coletiva. Necessita, portanto, ser orientada pela maior resolutividade dos problemas de saúde das populaçóes, ocupando lugar central e finalístico nas políticas de saúde, permitindo a construção da acessibilidade da atenção e do sistema de saúde, incluindo as pessoas com deficiência, entendidas como cidadãos de direitos (CECCIM, 2005).

A metodologia empregada no exercício da Educação Permanente visa superar o modelo tradicional de educação bancária - que visa à transmissão do saber de forma passiva, em que apenas um sujeito é detentor do conhecimento, responsável por repassar aos demais - através de novos conceitos de aprendizagem que proporcionam avaliaçôes críticas, reflexôes e açôes dos profissionais. Articulando teoria e prática, resultam em melhorias nos processos de trabalho, possibilitando movimentos e delineamentos de acordo com as necessidades encontradas nas diferentes realidades dos ambientes ocupacionais (CECCIM; FERLA, 2008; PINHEIRO; AZAMBUJA; BONAMIGO, 2018).

Não obstante, pode-se observar, na fala que segue, a ocorrência de momentos de capacitação e construção conjunta de conhecimentos voltados ao cuidado das PcDs, que muitas vezes não são compreendidos como educativos, em âmbito coletivo, por se darem em espaços informais ou com colegas de trabalho. Entretanto, momentos conjuntos que geram discussôes acerca dos formatos de trabalho vigentes e resultam em questionamentos e mudanças dos modos de articulação dos trabalhos, são formas de Educação Permanente (BATISTA; FERÇA, 2008): 
[...] Eu tenho uma colega que ela é surda-muda e trabalha na lavanderia com o pessoal, eu nem sei há quantos anos e as pessoas desenvolveram novas habilidades com ela, e ela acabou desenvolvendo algumas formas de se comunicar diferente do tradicional, libras, e de outras coisas que ela usava de mímicas também e ela treinou os colegas para saberem trabalhar com ela [...] (C3).

Assim, a EPS se destaca nessa compreensão, pois os autores Batista e Ferça (2008) apresentam uma ligação entre educação/trabalho/cidadania, através da superaçáo do processo de ensino-aprendizagem para uma política de educação e saúde, reforçando a ligação política entre saúde e educação. Além disso, para que a EPS se torne realidade, são necessários alguns ajustes no que diz respeito aos processos educativos, como, por exemplo, a superação da cultura da educação bancária através da pedagogia da problematizaçáo, que, segundo Paulo Freire, coloca o indivíduo como protagonista, e não como mero espectador da construçáo do conhecimento (PINHEIRO; AZAMBUJA; BONAMIGO, 2018).

\section{Perspectivas dos trabalhadores acerca das temáticas de EPS}

Espaços de formação proporcionam aos profissionais avanços que englobam o conhecimento e reforçam suas experiências, fortalecendo a Rede de Cuidados da Pessoa com Deficiência e auxiliando na qualificação dos atendimentos prestados (KINKER, MOREIRA; BERTUOL, 2018). Cursos e capacitaçóes são compreendidos como fator mobilizador da inércia profissional, uma vez que possibilitam a atualização desses trabalhadores, qualificação para o desenvolvimento de açóes mediante as demandas dos usuários do SUS, bem como a melhora de seus currículos, resultando nos reais objetivos propostos pelas EPS (PEREIRA; SENA, 2016).

Na perspectiva dessa abordagem, no presente estudo, alguns sujeitos apontaram sugestóes de temas para as ações de Educação Permanente em Saúde com enfoque na pessoa com deficiência, como mostra a tabela 4 . 
Tabela 4. Sugestôes de temas em Educação Permanente em Saúde. Região 28 de Saúde - Rio Grande do Sul, 2017

\begin{tabular}{l|c|c|c|c|c|c|c|c}
\hline \multicolumn{1}{|c|}{ TEMAS } & $\begin{array}{c}\text { Profissionais } \\
(\mathbf{p})\end{array}$ & $\%$ & $\begin{array}{c}\text { Coordenadores } \\
(\mathbf{c})\end{array}$ & $\%$ & $\begin{array}{c}\text { Secretários } \\
\text { municipais de } \\
\text { saúde (s) }\end{array}$ & $\%$ & Total & $\%$ \\
\hline $\begin{array}{l}\text { Atençáo } \\
\text { integral à } \\
\text { saúde }\end{array}$ & 3 & 8,6 & 1 & 2,8 & 1 & 2,8 & $\mathbf{5}$ & $\mathbf{1 4 , 3}$ \\
\hline \begin{tabular}{l} 
Temas gerais \\
\hline autismo
\end{tabular} & 3 & 8,6 & 7 & 20 & 0 & 0 & $\mathbf{1 0}$ & $\mathbf{2 8 , 6}$ \\
\hline $\begin{array}{l}\text { deficiências } \\
\text { físicas }\end{array}$ & 1 & 2,8 & 0 & 0 & 0 & 0 & $\mathbf{1}$ & $\mathbf{2 , 8}$ \\
\hline $\begin{array}{l}\text { síndrome } \\
\text { down }\end{array}$ & 0 & 0 & 1 & 2,8 & 0 & 0 & $\mathbf{1}$ & $\mathbf{2 , 8}$ \\
\hline Direitos pcd & 1 & 2,8 & 1 & 2,8 & 2 & 5,7 & $\mathbf{4}$ & $\mathbf{1 1 , 3}$ \\
\hline Inclusão & 2 & 5,7 & 2 & 5,7 & 2 & 5,7 & $\mathbf{6}$ & $\mathbf{1 7 , 5}$ \\
\hline $\begin{array}{l}\text { Integraçáo } \\
\text { serviços/rede }\end{array}$ & 1 & 2,8 & 4 & 11,4 & 0 & 0 & $\mathbf{5}$ & $\mathbf{1 4 , 3}$ \\
\hline Libras & 0 & 0 & 1 & 2,8 & 1 & 2,8 & $\mathbf{2}$ & $\mathbf{5 , 6}$ \\
\hline Total & 11 & 18 & & 6 & & 35 & 100 \\
\hline Font dados
\end{tabular}

Fonte: dados da pesquisa, 2017.

Os sujeitos $(\mathrm{n}=29)$ trouxeram temáticas específicas, em sua maioria voltadas aos direitos e prerrogativas das pessoas com deficiências, inclusão, cuidados à saúde, integração entre os serviços de reabilitação. Também foram referidas temáticas voltadas ao preparo psicológico dos profissionais de saúde para a assistência à $\mathrm{PcD}$. Capacitaçóes para os profissionais e integraçáo dos serviços foram mencionadas pela maioria ( $n=11)$ dos coordenadores de Serviços de Reabilitação; já os profissionais de saúde mencionaram temáticas voltadas à atenção integral da pessoa com deficiência.

Os dados acima, provenientes dos questionários, conferem com os relatos dos sujeitos entrevistados, que enfatizam a necessidade da abordagem da inclusão e do preparo do profissional de saúde para o atendimento às pessoas com deficiência:

Se nós tivéssemos um tema, olha, eu acho que tá faltando abrir pro pessoal o que é realmente inclusão. A inclusão com responsabilidade, e não incluir só por incluir. [...] (C2). 
[...] podia ter um treinamento de como tratar essa pessoa. Não só os pacientes, mas principalmente os familiares e os responsáveis por essas crianças que têm deficiência. Cada um age de uma maneira, mas nem sempre a gente tá treinado, capacitado pra isso. [...] (P14)

Alguns estudos evidenciaram que os profissionais entrevistados sugerem temáticas como "abordagem familiar, relação interpessoal, cuidado com feridas, tabagismo, vacinação, internação domiciliar e conceitos e metodologias de abordagem em grupos" (KINKER; MOREIRA; BERTUOL, 2018, p. 6). Desse modo, verificase que não existem sugestôes de abordagens que englobam a temática "pessoa com deficiência” e, sim, questões biomédicas, técnicas e gerenciais. As sugestões de ações educativas permanentes são elencadas como estratégia para o aperfeiçoamento do serviço prestado a essa população. Além disso, constitui importante ferramenta para a transformação do cuidado e o desenvolvimento crítico, reflexivo e técnico dos trabalhadores da Rede, indo ao encontro do que preconiza a PNEPS (CARVALHO; ALMEIDA; BEZERRA, 2016). Nesse contexto, torna-se evidente o fortalecimento da qualificação da Rede de Cuidados à Pessoa com Deficiência quando desenvolvidas tais açôes educativas, levando em consideração os achados da presente pesquisa e o cruzamento de informaçóes com os autores supracitados.

Levando em consideração as ideias anteriores, ainda se faz presente a necessidade de preparo e construção permanente das temáticas que englobam a capacitação profissional de trabalhadores, que se articulam com a atençáo à pessoa com deficiência. Sob esse prisma, a necessidade, liberdade, autonomia e prazer dos profissionais pela procura de temáticas de maior interesse, sem deixar de cumprir os compromissos. Além da busca por inovar e transformar seu ambiente e realidade de trabalho, culminam em integralidade efetiva dos serviços, potencialização de açôes e, consequentemente, melhoria em atendimentos que abarcam a inclusão e às PCDs de forma científica e qualificada. Com a autonomia oportunizada pelas ações da Educação Permanente, os profissionais também se sentem valorizados em seu ambiente de trabalho e estimulados positivamente (ALVES; RIBEIRO; SAMPAIO, 2016).

Por outro lado, alguns estudos indicam certa resistência no atendimento de pessoas com deficiência por parte dos profissionais da saúde, que pode ser atribuída à falta de preparo profissional adequado e de conhecimento acerca da temática. Assim, a partir das consideraçóes desses estudos, mostra-se a importância de realizar açóes de educação permanente em saúde no cotidiano dos trabalhadores de saúde que deem 
conta das demandas e das necessidades no ambiente de trabalho e das pessoas com deficiência, usuários dos serviços (CARDOSO, 2011; SIRDÊNIA et al., 2013).

\section{Considerações finais}

A investigação sobre as ações e estratégias de Educação Permanente em Saúde na Rede de Cuidados à Pessoa com Deficiência em uma região de saúde do estado do Rio Grande do Sul evidenciou que, apesar de esta ser uma importante ferramenta para a qualificação das práticas profissionais, a maioria dos trabalhadores de saúde não tem participado de tais açôes, pois os achados evidenciaram que os municípios estudados não oferecem atividades educativas nesse enfoque. Identificou-se também que os entrevistados não reconhecem como açóes de Educação Permanente os momentos de discussões em equipe, como as conversas multiprofissionais que se estruturam nos ambientes informais do trabalho, explicitando que apenas são identificadas as formas mais tradicionais desse contexto, caracterizadas pela presença de agentes centrais de disseminação das informaçôes.

Desse modo, as dificuldades da efetivação das açôes de Educação Permanente em Saúde foram justificadas pelas inadequadas estruturas físicas dos serviços de saúde e baixo quantitativo de profissionais na equipe. Outrossim, chamaram atenção a pequena quantidade de profissionais envolvidos e o reduzido interesse com a temática da pessoa com deficiência, demarcados pela não participação ativa dos usuários dos serviços em ações desse campo temático. Foi possível observar o reconhecimento das fragilidades nas atividades educativas que visem melhorias dos processos de trabalho e atendimento em saúde, levando em consideração a necessidade de maior compreensão da temática para a assistência qualificada à saúde desse segmento populacional. Compreende-se que essa percepção é um marco importante para a efetivação de mudanças e qualificação no atendimento à pessoa com deficiência.

A partir desses contextos, pontua-se que são indispensáveis reflexóes constantes dos trabalhadores, coordenadores, gestores dos serviços de saúde e pessoas com deficiência usuárias dos serviços, a fim de que possam reconhecer as diversas açóes educativas permanentes já existentes em seus ambientes de trabalho, interpretandoas e transpondo-as à prática cotidiana do trabalho em atenção à saúde da pessoa com deficiência. ${ }^{1}$ 


\section{Referências}

ALVES, M. A.; RIBEIRO, F. F.; SAMPAIO, R. F. Potencial de mudança nas práticas de saúde: a percepção de trabalhadores de uma Rede de Reabilitação em (trans)formação. Fisioterapia e Pesquisa, v. 23, p. 185-192, 2016.

AMORIM, E. G.; LIBERALI, R.; MEDEIROS NETA, O. M. Avanços e desafios na atenção à saúde de pessoas com deficiência na atenção primária no Brasil: uma revisão integrativa, v. 1, n. 13, 2018.

BARDIN L. Análise de conteúdo. 1.ed. Lisboa: Ediçôes 70, 2016.

BATISTA, K. B. C.; GONÇALVES, O. S. J. Formação dos profissionais de saúde para o SUS: significado e cuidado. Saúde e Sociedade, v. 20, p. 884-899, 2011.

BRASIL. Ministério da Saúde Secretaria de Atenção à Saúde, Departamento de Açóes Programáticas Estratégicas. Política Nacional de Saúde da Pessoa com Deficiência. Brasília: MS, 2010a.

- Ministério da Saúde, Secretaria de Gestão do Trabalho e da Educação na Saúde, Departamento de Gestão da Educação em Saúde. Política Nacional de Educação Permanente em Saúde. Brasília: MS, 2009.

. Ministério da Saúde. Instrutivo de reabilitação auditiva, física, intelectual e visual.

Ministério da Saúde, 2020. Disponível em: https://www.saude.gov.br/images/pdf/2020/ August/10/Instrutivo-de-Reabilitacao-Rede-PCD-10-08-2020.pdf. Acesso em 02 set. 2020.

. Ministério da Saúde. Política Nacional de Saúde da Pessoa com Deficiência. Brasília, DF: Ministério da Saúde, 2010b.

. Ministério da Saúde. Portaria no 1. 996, de 20 de agosto de 2007. Dispôe sobre as diretrizes para a implementação da Política Nacional de Educação Permanente em Saúde. Diário Oficial da União, 2007.

. Ministério da Saúde. Portaria no 793, de 24 de abril de 2012. Institui a Rede de Cuidados à Pessoa com Deficiência no âmbito do Sistema Único de Saúde. Diário Oficial da União, 2012.

CARDOSO, A. O Acesso ao Cuidado em Saúde Bucal para Crianças com Deficiência Motora: Perspectivas dos Cuidadores. Pesq. Bras. Odontoped. Clin. Integr., v. 11, n. 4, p. 593-599, 2011.

CARVALHO, T. G. S.; ALMEIDA, A. M. B.; BEZERRA, M. I. C. Percepção dos profissionais de saúde da atenção primária sobre educação permanente em saúde. SANARE, 2016

CAVALCANTI, Y. W.; PADILHA, W. W. N. Qualificação de processos de gestão e atenção no município de Caaporã, PB: relatos de tutoria de educação permanente em saúde. Revista Saúde em Debate, v. 38, p. 170-80, 2014. 
CECCIM, R. Educação Permanente em Saúde: desafio ambicioso e necessário. 2005.

CECCIM, R. B.; FERLA, A. A. Educação e saúde: ensino e cidadania como travessia de fronteiras. Trabalho, Educação e Saúde, v. 6, p. 443-456, 2008.

DUBOW, C. Análise da implementação da rede de cuidados à saúde da pessoa com deficiência na $28^{a}$ região de saúde do Estado do Rio Grande do Sul [dissertação]. Santa Cruz do Sul: Universidade de Santa Cruz do Sul; 2017. 138p.

DUBOW, C.; GARCIA, E. L.; KRUG, S. B. F. Percepçóes sobre a Rede de Cuidados à Pessoa com Deficiência em uma Regiāo de Saúde. Revista Saúde em Debate, v. 42, p. 455-67, 2018.

FORTUNA, C. M. et al. Continuing education in the family health strategy: rethinking educational groups. Revista Latino-Americana de Enfermagem, v. 21, p. 990-997, 2013.

GOFFMAN, E. Estigma: notas sobre a manipulação da identidade deteriorada. 4ed. Rio de Janeiro: Editora Livros Técnicos e Científicos; 2012.

INSTITUTO BRASILEIRO DE GEOGRAFIA E ESTATÍSTICA. Censo Demográfico 2010: Banco de Dados agregados do IBGE. Rio de Janeiro: IBGE; Disponível em: http://www.ibge. gov.br/home/estatistica/populacao/censo2010/default.shtm. Acesso em: 15 maio. 2019

KINKER, F. S.; MOREIRA, M. I. B.; BERTUOL, C. O desafio da formação permanente no fortalecimento das Redes de Atenção Psicossocial. Interface - Comunicação, Saúde, Educação, v. 22, p. 1247-1256, 2018.

MACHADO, J. F. P. et al. Educação Permanente no cotidiano da Atenção Básica no Mato Grosso do Sul. Saúde em Debate, v. 39, p. 102-113, 2015.

MACHADO, W. C. A. et al. Integralidade na Rede De Cuidados da Pessoa com Deficiência. Texto \& Contexto - Enfermagem, v. 27, 2018

MENDES, V. L. F. Da "narrativa da dificuldade" ao diálogo com a diferença: construindo a Rede de Cuidados à Saúde da Pessoa com Deficiência Brasil. In: BRASIL. Ministério da Saúde. Diálogo (bio)político: sobre alguns desafios da construção da Rede de Cuidados à Saúde da Pessoa com Deficiência do SUS. Brasília: Livrograf, dez., 2014.

PEIXOTO, L. S. Educação permanente, continuada e em serviço: desvendando seus conceitos. Enfermeria Global, v. 29, 2013.

PEREIRA, L. D. A.; SENA, R. Cursos realizados pelo Canal Minas Saúde: percepçóes dos profissionais que atuam na atenção primária. Revista Gaúcha de Enfermagem, v. 37, 2016.

PERES, C.; SILVA, R.; BARBA, P. D. Desafios e potencialidades do processo de educação permanente em saúde. Trabalho, Educação e Saúde., v. 14, p. 783-801, 2016.

PINHEIRO, G. E. W.; AZAMBUJA, M.; BONAMIGO, A. W. Facilidades e dificuldades vivenciadas na Educação Permanente em Saúde, na Estratégia Saúde da Família. Saúde em Debate, v. 42, p. 187-197, 2018. 
QUEIROZ, D.; SILVA, M. R.; OLIVEIRA, L. Educação Permanente com Agentes Comunitários de Saúde: potencialidades de uma formação norteada pelo referencial da Educação Popular e Saúde. Interface - Comunicação, Saúde, Educação, v.18, p. 1199-1210, 2014.

SANTOS, W. Deficiência como restrição de participação social: desafios para avaliação a partir da Lei Brasileira de Inclusão. Ciência \& Saúde Coletiva, v. 21, n.10, p. 3007-3015, 2016.

SANTOS, M. L. R.; RAMOS, N.; QUEIROZ, G. S. Educação Permanente em Saúde no Brasil na modalidade EAD: produção científica em periódicos, Revista EDaPECI - Educação a Distância e Práticas Educativas Comunicacionais e Interculturais v.17, n. 03, p.15, 2017.

SEMA, R. et al. Educação permanente nos serviços de saúde: atividades educativas desenvolvidas no estado de Minas Gerais, Brasil. Revista Gaúcha de Enfermagem, v. 38, 2017.

SILVA, K. et al. Análise dos discursos referentes à Educação Permanente em Saúde no brasil (1970 a 2005). Trabalho, Educaçâo e Saúde, v. 17, 2019.

SILVA, L. A. et al. Avaliação da educação permanente no processo de trabalho em saúde. Revista Trabalho, Educação e Saúde, v.14, p. 765-781, 2016.

SIRDÊNIA, D. et al. Acessibilidade de crianças com deficiência aos serviços de saúde na atenção primária Revista Eletrônica de Enfermagem, v. 15, n. 3, 2013.

TEDESCO, J. D. R.; JUNGES, J. R. Desafios da prática do acolhimento de surdos na atenção primária. Cadernos de Saúde Pública, v. 29, p. 1685-1689, 2013.

VERMELHO, S. C.; FIGUEIREDO, G. A percepção de secretários municipais de saúde sobre a gestão do trabalho e da educação na rede pública do Sistema Único de Saúde (SUS). Saúde soc., São Paulo, v. 26, n. 2, p. 382-396, jun. 2017.

\section{Nota}

${ }^{1}$ S. B. F. Krug, G. Mocelin, M. C. Magedanz, B. R. de Oliveira e C. Dubow: concepção, delineamento, análise e interpretação dos dados; redação e revisão crítica do artigo; e aprovação da versão a ser publicada. 


\section{Abstract}

\section{Actions and strategies for permanent health} education in the care network for people with disabilities

To investigate actions and strategies of Permanent Health Education (PHE) in Network Care for People with Disability (PwD), from the perspective of health workers and managers. Exploratory research, type of case study, with mixed approach, carried out in the 13 municipalities of the Health Region 28 of Rio Grande do Sul. The questionnaires were analyzed with descriptive statistics, in absolute and relative frequencies, and the interviews by Content Analysis were composed, culminating in three thematic categories. The results showed that The PHE in the PwD Care Network constitutes a tool for the qualification of professional practices, however, most workers do not participate in these actions, because the municipalities do not offer them. It was identified that the subjects do not recognize daily work situations, spaces, and informal moments, such as PHE actions. The difficulties of PHE actions were justified by inadequate physical structures of the services and low number of professionals in the team. A small number of professionals involved and reduced interest with the theme of PwD was identified, demarcated by the non-active participation of service users in actions in this field. Thus, reflections that recognize educational actions in work environments are indispensable, transforming them into daily practices of health care of PwD.

Keywords: people with disabilities; Unified Health System; work; education; health care. 